\title{
Effect of Impervious Zone Width of an Embankment Dam on Blanket Design Length
}

\author{
Masayuki Fujihara ${ }^{1}$, Noriyuki Kobayashi ${ }^{2}$, Tatsuro Nishiyama ${ }^{2}$, Tomoki Izumi ${ }^{3}$ \\ and Yoshitaka Yoshitake ${ }^{4}$
}

\begin{abstract}
This paper investigates applicability of the method determining blanket design length based on the analytical solution proposed by Yoshitake et al. (2011) to smaller embankment dams, and demonstrates its validity to the application of half-size of the dams employed in the previous study through the comparison with results computed by $\mathrm{BEM}$. Then, the reason why the resultant design blanket length of smaller dams is always larger than that of larger ones is investigated by introducing the idea of effective seepage path length. This investigation reveals that the effective seepage path lengths of the half-sized dams are almost the same as those of the original dams, keeping the high accuracy of analysis compared to the BEM solution.
\end{abstract}

Keywords: Soil blanket; Effective seepage path length; Embankment dam

\section{Introduction}

Impervious soil blankets are widely used as measures against seepage from reservoirs of embankment dams or irrigation tanks on pervious foundations. In the case of rectangular soil blankets, the method proposed by Bennett (1946) has been employed to decide the design blanket length and thickness. This is because Matsumoto and Yamaguchi (1989) showed that the relationship between the blanket length and the seepage discharge obtained by the Bennett method sufficiently coincides with that by Finite Element Method (FEM).

Though all the constructed soil blankets are rectangular-shaped, Yoshitake et al. (2011) demonstrated an analytical solution of a seepage model for a triangular blanket and revealed that triangular soil blankets are more effective against the seepage than rectangular ones. If the triangular blanket is employed instead of rectangular one, $31 \%$ of the blanket material can be saved, while keeping the same seepage discharge (Fujihara et al. (2011)). And provided that the same volume of blanket material is used, minimum seepage discharge through the optimum triangular blanket is always less than that through the optimum rectangular one (Kobayashi et al. (2011)). In addition, the method proposed by Yoshitake et al. (2011), which was validated through comparison with the results obtained by Boundary Element Method (BEM), can be employed to decide the design length of triangular blanket.

This paper investigates applicability of the method determining blanket design length based on the analytical solution proposed by Yoshitake et al. (2011) to smaller em-

\footnotetext{
${ }^{1}$ Professor, Faculty of Agriculture, Ehime University, 3-5-7 Tarumi, Matsuyama, Ehime 790-8566, Japan

${ }^{2}$ Associate Professor, Faculty of Agriculture, Ehime University, 3-5-7 Tarumi, Matsuyama, Ehime 790-8566, Japan

${ }^{3}$ Assistant Professor, Faculty of Agriculture, Ehime University, 3-5-7 Tarumi, Matsuyama, Ehime 790-8566, Japan

${ }^{4}$ Professor, Faculty of Agriculture, Ehime University, 3-5-7 Tarumi, Matsuyama, Ehime 790-8566, Japan (Corresponding Author) E-mail: ynkt1214@agr.ehime-u.ac.jp
}

bankment dams, and demonstrates its validity to the application of half-size of the dams employed in the previous study through the comparison with results computed by BEM. Then, the reason why the resultant design blanket length of smaller dams is always larger than that of larger ones is investigated by introducing the idea of effective seepage path length.

\section{Method and analysis cases}

Figure 1 shows diagrams with symbols used in the model of rectangular and triangular blankets. The symbols are defined as follows: the bottom width of impervious zone is $B$, the water depth of the reservoir $H$ (= level difference between the water surface in the reservoir and the top of pervious foundation), the thickness of foundation $D_{f}$, the thickness of the blanket at the upstream toe of impervious zone $D_{b}$, the permeability coefficients of the foundation and the blanket $k_{f}\left(=10^{-5} \mathrm{~m} / \mathrm{s}\right)$ and $k_{b}\left(=10^{-7} \mathrm{~m} / \mathrm{s}\right)$, respectively, and the length of blanket $L$.

Following Bennett (1946), the seepage discharge $\left(q_{4}\right)$ of the rectangular blanket can be expressed as a function of the blanket length $L$ as follows;

$$
q_{4}(L)=\frac{k_{f} D_{f} H}{B+\frac{1}{a} \tanh (a L)}=\frac{k_{f} D_{f} H}{B+L_{e}}
$$

where

$$
a=\sqrt{\frac{k_{b}}{k_{f} D_{f} D_{b}}}
$$

Following Yoshitake et al. (2011), the seepage discharge $\left(q_{3}\right)$ of the triangular blanket can be similarly expressed as a function of the blanket length $L$ as follows; 


$$
q_{3}(L)=\frac{k_{f} D_{f} H}{B+\frac{1}{a} \frac{I_{1}(2 a L)}{I_{0}(2 a L)}}=\frac{k_{f} D_{f} H}{B+L_{e}}
$$

where the symbols $I_{0}$ and $I_{1}$ denote the modified Bessel functions of the first kind of zero order and first order, respectively. The symbol $L_{e}$ in both Eqs.(1) and (3) means seepage resistance of a blanket and is called "effective seepage path length under the blanket". The value $L_{e}$ is considered as an impervious blanket length equivalent to the soil blanket length $L$.

BEM model used in this study for the validation of analytical method described above is the same as the one employed in the research conducted by Yoshitake et al. (2011). In the BEM model, the upstream slope and the downstream slope of the impervious zone are the same at 1:0.15. The width of impervious zone is $4 \mathrm{~m}$ at the water surface level. It is also assumed that the permeability coefficients of impervious zone $\left(k_{c}\right)$ and the blanket $\left(k_{b}\right)$ are equal $\left(k_{c}=k_{b}\right.$ $\left.=10^{-7} \mathrm{~m} / \mathrm{s}\right)$, since the same soil material is practically used for both the impervious zone and the blanket. In order to neglect the influence of inflow from the upper reach of the reservoir, the object domain is extended as far as the range of $270 \mathrm{~m}$ upstream and of $75 \mathrm{~m}$ downstream from the downstream end of the impervious zone. The seepage analysis cases conducted in this research are tabulated in Table 1. In all the cases, the bottom width of impervious zone is $10.0 \mathrm{~m}$ long and water depth of the reservoir is $20.0 \mathrm{~m}$. The thicknesses of blanket and foundation are changing parameters.

\section{Results}

Figure 2 shows relation between the blanket length and the seepage discharge of the cases A1-2, A2-2, and A3-2. The symbols $q_{3 B E M}$ and $q_{4 B E M}$ in Figure 2 denote the computed seepage discharges by BEM through triangular and rectangular blankets, respectively. Figure 2 illustrates that for smaller value of blanket length, the discharge decreases sharply as the blanket length increases, while it decreases gradually for larger value of the blanket length. By comparing Figures 2(a) to (c), it is found that seepage discharge increases as the thickness of foundation increases.

It also shows that the difference between the analytical solutions by Eqs.(1) and (3) and the results by BEM becomes small enough when $L$ becomes greater than a certain length, say $30 \mathrm{~m}$ for the case A1-2. In other words, this means that the analytical solutions by Eqs.(1) and (3) are only reliable when the blanket length is long enough. To investigate this more in detail, the index $r$, which is the ratio of the difference between the analytical discharge $(q)$ and the corresponding BEM result $\left(q_{B E M}\right)$ at the same blanket length $L$, is introduced.

$$
r=\frac{q-q_{B E M}}{q_{B E M}}
$$

When $r=0.1$, the value of analytical solution is larger than that of BEM solution by $10 \%$; the value of analytical solu-

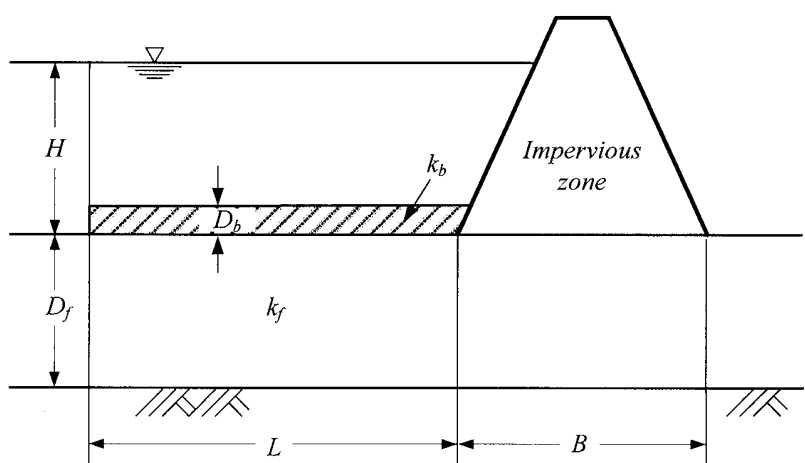

(a) Rectangular blanket

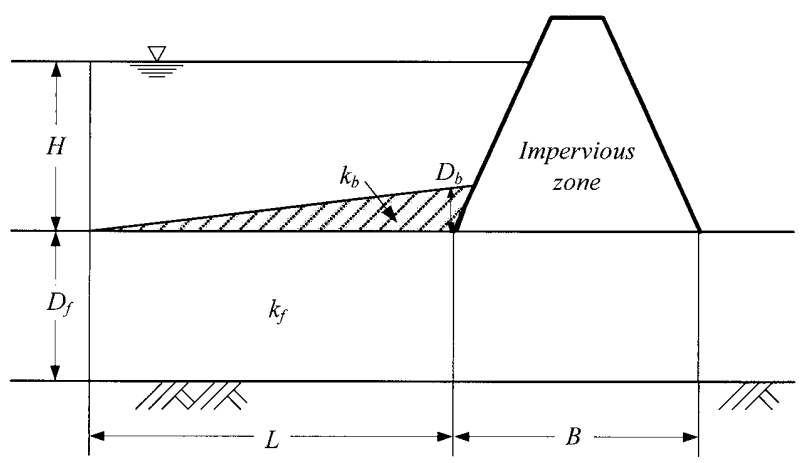

(b) Triangular blanket

Figure 1: Sketches of embankment dams with blanket

\begin{tabular}{|c|c|c|c|c|c|}
\hline \multirow{2}{*}{ Case } & \multicolumn{2}{|c|}{$D_{b}(\mathrm{~m})$} & \multirow{2}{*}{$D_{f}(\mathrm{~m})$} & \multirow{2}{*}{$B(\mathrm{~m})$} & \multirow{2}{*}{$H(\mathrm{~m})$} \\
\hline & Tri & $\operatorname{Rec}$ & & & \\
\hline Al-1 & 4.0 & 2.0 & \multirow{3}{*}{10.0} & \multirow{9}{*}{10.0} & \multirow{9}{*}{20.0} \\
\hline A $1-2$ & 6.0 & 3.0 & & & \\
\hline Al-3 & 8.0 & 4.0 & & & \\
\hline A2-1 & 4.0 & 2.0 & \multirow{3}{*}{20.0} & & \\
\hline A2-2 & 6.0 & 3.0 & & & \\
\hline A2-3 & 8.0 & 4.0 & & & \\
\hline A3-1 & 4.0 & 2.0 & \multirow{3}{*}{30.0} & & \\
\hline A3-2 & 6.0 & 3.0 & & & \\
\hline A3-3 & 8.0 & 4.0 & & & \\
\hline
\end{tabular}

Table 1: Experimental Cases

Tri: Triangular blanket, Rec: Rectangular blanket

tion becomes identical to that of BEM solution at $r=0.0$.

Table 2 shows the blanket length calculated by Eqs.(1) and (3) at $r=0.1,0.05,0$, and -0.05 . From the table, we can find out the following: (a) For the cases A1-1, A1-2, and A1-3, the seepage discharges calculated by Eqs.(1) and (3) are reliable when the lengths of both triangular and rectangular blankets are over $30 \mathrm{~m}$; (b) For the cases A2-1, A2-2, and A2-3, where the thickness of foundation is $20.0 \mathrm{~m}$, the blanket length of over $80 \mathrm{~m}$ is necessary to make the difference between seepage discharges calculated by Eqs.(1) and (3) and those by BEM small enough, while 


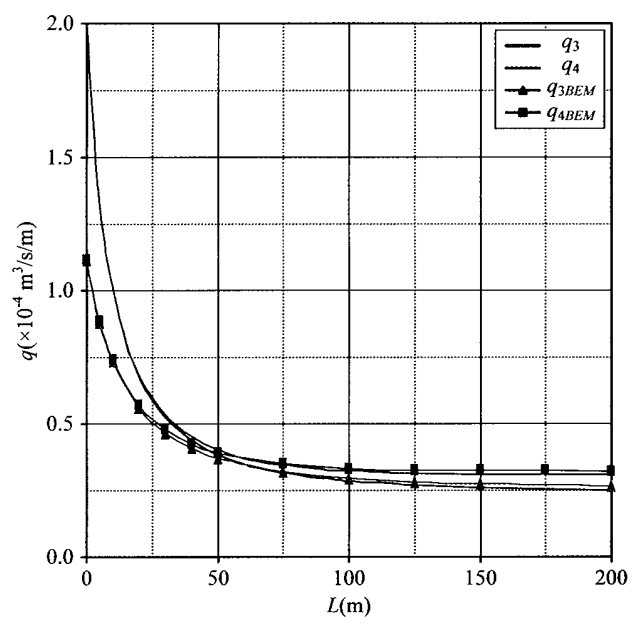

(a) Case A1-2

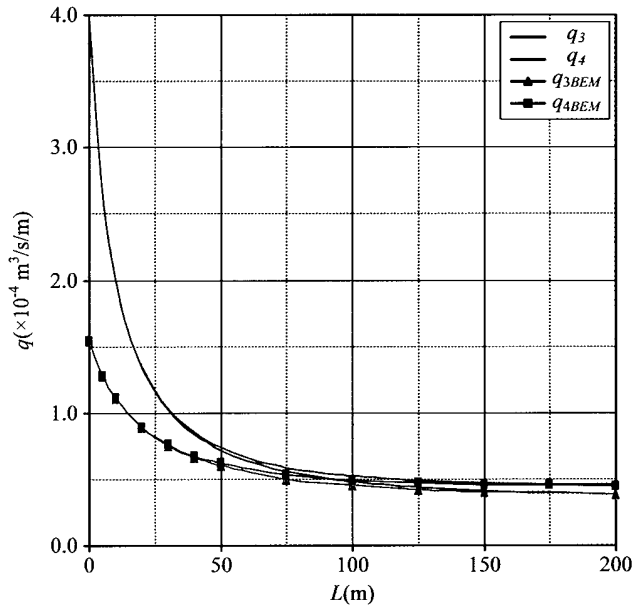

(b) Case A2-2

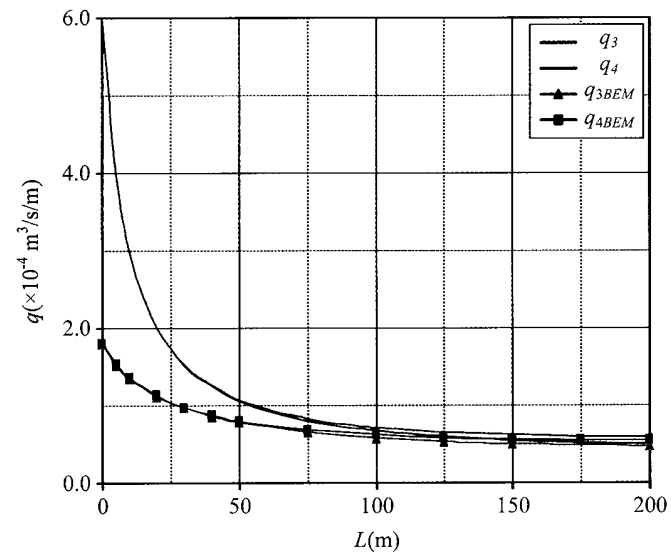

(c) Case A3-2

Figure 2: Relation between blanket length seepage discharge of cases A1-2, 2-2 and 3-2.

blanket lengths calculated by Eqs.(1) and (3) are always larger than those computed by BEM; and (c) For the cases A3-1, A3-2, and A3-3, where the thickness of foundation is $30.0 \mathrm{~m}$, the blanket length of over $130 \mathrm{~m}$ is necessary to
Table 2: Blanket lengths calculated by Eq.(1) and (3) at $r=0.1,0.05,0.0$ and -0.05 .

\begin{tabular}{|c|r|r|r|r|c|c|c|c|}
\hline \multirow{2}{*}{ Case } & \multicolumn{2}{|c|}{$r=0.1$} & \multicolumn{2}{c|}{$r=0.05$} & \multicolumn{2}{c|}{$r=0.0$} & \multicolumn{2}{c|}{$r=-0.05$} \\
\cline { 2 - 9 } & Tri & Rec & Tri & Rec & Tri & Rec & Tri & Rec \\
\hline A1-1 & 33.0 & 32.0 & 44.0 & 43.0 & 69.0 & 70.0 & - & - \\
\hline A1-2 & 35.0 & 33.0 & 47.0 & 44.0 & 71.0 & 67.0 & 200.0 & - \\
\hline A1-3 & 37.0 & 34.0 & 50.0 & 45.0 & 75.0 & 67.0 & 193.0 & 158.0 \\
\hline A2-1 & 77.0 & 79.0 & 120.0 & - & - & - & - & - \\
\hline A2-2 & 79.0 & 79.0 & 115.0 & 120.0 & - & - & - & - \\
\hline A2-3 & 83.0 & 80.0 & 117.0 & 113.0 & - & - & - & - \\
\hline A3-1 & 134.0 & 200.0 & - & - & - & - & - & - \\
\hline A3-2 & 132.0 & 140.0 & - & - & - & - & - & - \\
\hline A3-3 & 132.0 & 132.0 & - & - & - & - & - & - \\
\hline
\end{tabular}

Tri: Triangular blanket, Rec: Rectangular blanket - : no corresponding data

keep the high accuracy of seepage analysis, while there are no corresponding results to $r=0.05,0.0$ and -0.05 .

\section{Discussion}

To compare the results obtained in this study with those of Yoshitake et al. (2011), experimental cases and the results of Yoshitake et al. (2011) are summarized in Tables 3 and 4. In the cases of Yoshitake et al. (2011), both the bottom width of the impervious zone and the water depth of the reservoir are twice as big as the cases conducted in this study, while other parameters are the same values as used in this study. Hereafter the cases conducted in this study refer to as "A" series (Table 1) and those conducted by Yoshitake et al. (2011) as "B" series (Table 3).

By comparing Table 2 with Table 4, we can easily find that all the values of the blanket length in Table 2 are larger than the corresponding ones in Table 4 . This seems strange and opposite at first glance because both the impervious zone and the reservoir in case "A" series are smaller than those in "B" series.

To investigate the apparent difference of blanket lengths in Tables 2 and 4, the effective seepage path length under the blanket $L_{e}$ and the value of effective seepage path length, $B+L_{e}$, which corresponds to the denominator of both Eqs.(1) and (3), of both cases " $A$ " and "B" series are tabulated in Table 5. The ratios of the values in " $B$ " series to those in " $\mathrm{A}$ " series are also calculated and listed in shaded columns in Table 5.

It is clearly revealed from Table 5 that all those ratios of the effective seepage path length are between 0.90 and 1.11 . This means the values of the effective seepage path length in the case " $\mathrm{A}$ " series is almost the same as those corresponding values in the case " $\mathrm{B}$ " series, even though the scale of impervious zone of the latter is twice larger than the former. The bottom width of impervious zone in the case " $\mathrm{A}$ " series is smaller than that in the case " $\mathrm{B}$ " series and, consequently, the blanket length in the case " $\mathrm{A}$ " series becomes larger than those in the case "B" series. 
If the length of the blanket extends to infinity, the effective seepage path length approaches to the value $B+a^{-1}$. The ratios of effective seepage path lengths in " $B$ " series to those in "A" series at $L=\infty$ are listed in Table 6. The calculated ratios are between 1.06 and 1.18 . Since the val-

Table 3: Experimental Cases of Yoshitake et al. (2011)

\begin{tabular}{|c|c|c|c|c|c|}
\hline \multirow{2}{*}{ Case } & \multicolumn{2}{|c|}{$D_{b}(\mathrm{~m})$} & \multirow{2}{*}{$D_{f}(\mathrm{~m})$} & \multirow{2}{*}{$B(\mathrm{~m})$} & \multirow{2}{*}{$H(\mathrm{~m})$} \\
\hline & Tri & Rec & & & \\
\hline B1-1 & 4.0 & 2.0 & \multirow{3}{*}{10.0} & & \\
\hline B1-2 & 6.0 & 3.0 & & \\
\hline B1-3 & 8.0 & 4.0 & & & \\
\hline B2-1 & 4.0 & 2.0 & \multirow{2}{*}{20.0} & \multirow{2}{*}{20.0} & \multirow{2}{*}{40.0} \\
\hline B2-2 & 6.0 & 3.0 & & \\
\hline B2-3 & 8.0 & 4.0 & & & \\
\hline B3-1 & 4.0 & 2.0 & \multirow{2}{*}{30.0} & & \\
\hline B3-2 & 6.0 & 3.0 & & \\
\hline B3-3 & 8.0 & 4.0 & & & \\
\hline
\end{tabular}

Tri: Triangular blanket, Rec: Rectangular blanket ues of $a$ in the cases " $A$ " series are the same as those corresponding cases of " $\mathrm{B}$ " series, the discrepancy from the

Table 4: Blanket lengths calculated by Eqs.(1) and (3) at $r=0.1,0.05,0.0$ and -0.05 , after Yoshitake et al. (2011).

\begin{tabular}{|c|r|r|r|r|c|c|c|c|}
\hline \multirow{2}{*}{ Case } & \multicolumn{2}{|c|}{$r=0.1$} & \multicolumn{2}{c|}{$r=0.05$} & \multicolumn{2}{c|}{$r=0.0$} & \multicolumn{2}{c|}{$r=-0.05$} \\
\cline { 2 - 9 } & \multicolumn{1}{c|}{ Tri } & \multicolumn{1}{c|}{ Rec } & \multicolumn{1}{c|}{ Tri } & Rec & \multicolumn{1}{c|}{ Tri } & Rec & Tri & Rec \\
\hline B1-1 & 23.0 & 22.0 & 32.0 & 31.0 & 46.0 & 46.0 & 83.0 & 114.0 \\
\hline B1-2 & 24.0 & 23.0 & 34.0 & 32.0 & 49.0 & 47.0 & 79.0 & 79.0 \\
\hline B1-3 & 25.0 & 23.0 & 35.0 & 33.0 & 51.0 & 47.0 & 80.0 & 75.0 \\
\hline B2-1 & 63.0 & 64.0 & 87.0 & 95.0 & 200.0 & - & - & - \\
\hline B2-2 & 65.0 & 65.0 & 87.0 & 89.0 & 144.0 & 200.0 & - & - \\
\hline B2-3 & 67.0 & 66.0 & 89.0 & 88.0 & 137.0 & 142.0 & - & - \\
\hline B3-1 & 108.0 & 121.0 & 194.0 & - & - & - & - & - \\
\hline B3-2 & 107.0 & 112.0 & 156.0 & 200.0 & - & - & - & - \\
\hline B3-3 & 110.0 & 110.0 & 153.0 & 162.0 & - & - & - & - \\
\hline
\end{tabular}

Tri: Triangular blanket, Rec: Rectangular blanket - : no corresponding data

Table 5: Effective seepage path length and its ratio between cases " $A$ " and " $B$ " series

\begin{tabular}{|c|c|c|c|c|c|c|c|c|c|c|c|c|c|c|c|c|}
\hline \multirow{3}{*}{ Case } & \multicolumn{4}{|c|}{$r=0.1$} & \multicolumn{4}{|c|}{$r=0.05$} & \multicolumn{4}{|c|}{$r=0.0$} & \multicolumn{4}{|c|}{$r=-0.05$} \\
\hline & \multicolumn{2}{|c|}{ Triangular } & \multicolumn{2}{|c|}{ Rectangular } & \multicolumn{2}{|c|}{ Triangular } & \multicolumn{2}{|c|}{ Rectangular } & \multicolumn{2}{|c|}{ Triangular } & \multicolumn{2}{|c|}{ Rectangular } & \multicolumn{2}{|c|}{ Triangular } & \multicolumn{2}{|c|}{ Rectangular } \\
\hline & $L_{e}$ & $B+L_{e}$ & $L_{e}$ & $B+L_{e}$ & $L_{e}$ & $B+L_{e}$ & $L_{e}$ & $B+L_{e}$ & $L_{e}$ & $B+L_{e}$ & $L_{e}$ & $B+L_{e}$ & $L_{e}$ & $B+L_{e}$ & $L_{e}$ & $B+L_{e}$ \\
\hline A1-1 & 29.2 & 39.2 & 27.5 & 7.5 & 35.9 & 45.9 & 33.3 & 43.3 & 45.9 & 55.9 & 41.0 & 51.0 & - & - & - & - \\
\hline A1-2 & 31.9 & 41.9 & 29.5 & 39.5 & 40.0 & 50.0 & 36.5 & 46.5 & 51.8 & 61.8 & 46.0 & 56.0 & 69.5 & 79.5 & - & - \\
\hline A1-3 & 34.2 & 44.2 & 31.1 & 41.1 & 43.5 & 53.5 & 38.7 & 48.7 & 57.0 & 67.0 & 49.7 & 59.7 & 78.2 & 88.2 & 62.4 & 72.4 \\
\hline A2-1 & 57.8 & 67.8 & 53.6 & 63.6 & 70.1 & 80.1 & 一 & - & - & - & - & 一 & 一 & - & - & - \\
\hline A2-2 & 63.7 & 73.7 & 59.6 & 69.6 & 78.2 & 88.2 & 70.8 & 80.8 & - & - & 一 & - & 一 & 一 & - & 一 \\
\hline A2-3 & 69.1 & 79.1 & 63.8 & 0 & 84.9 & 94.9 & 76.2 & 86.2 & - & - & - & - & - & - & - & - \\
\hline A3-1 & 83.2 & 93.2 & 76.6 & & - & - & - & - & - & - & - & - & - & - & - & - \\
\hline A3-2 & 92.9 & 102.9 & 85.4 & | ד. & - & - & - & - & - & - & - & - & - & - & - & - \\
\hline A3-3 & 99.6 & 109.6 & 91.5 & 101.5 & - & - & - & - & - & - & - & - & - & - & - & - \\
\hline B1-1 & 21.6 & 41.6 & 20.4 & 40.4 & 28.5 & 48.5 & 26.8 & 46.8 & 37.0 & 57.0 & 34.6 & 54.6 & 49.2 & 69.2 & 44.2 & 64.2 \\
\hline B1-2 & 22.9 & 42.9 & 21.7 & 41.7 & 31.1 & 51.1 & 28.8 & 48.8 & 41.3 & 61.3 & 38.1 & 58.1 & 54.6 & 74.6 & 49.0 & 69.0 \\
\hline B1-3 & 24.1 & 44.1 & 22.0 & 42.0 & 32.6 & 52.6 & 30.3 & 50.3 & 44.2 & 64.2 & 39.9 & 59.9 & 59.0 & 79.0 & 52.5 & 72.5 \\
\hline B2-1 & 51.2 & 71.2 & 48.5 & 68.5 & 61.6 & 81.6 & 57.3 & 77.3 & 78.7 & 98.7 & - & - & - & - & - & - \\
\hline B2-2 & 55.7 & 75.7 & 53.1 & 73.1 & 67.6 & 87.6 & 63.3 & 83.3 & 85.3 & 105.3 & 76.6 & 96.6 & - & - & - & - \\
\hline B2-3 & 59.1 & 79.1 & 56.2 & 76.2 & 72.4 & 92.4 & 67.5 & 87. & 91.5 & 111.5 & 82.3 & 102.3 & - & - & - & - \\
\hline B3-1 & 75.9 & 95.9 & 70.9 & 90.9 & 92.4 & 112.4 & - & - & - & - & - & - & 二 & - & - & - \\
\hline B3-2 & 83.0 & 103.0 & 78.5 & 98.5 & 99.9 & 119.9 & 92.1 & 112. & - & - & - & - & - & - & - & - \\
\hline B3-3 & 89.2 & 109.2 & 83.6 & 103.6 & 107.5 & 127.5 & 98.7 & 118.7 & - & - & - & - & - & - & - & 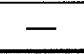 \\
\hline B.Al & & & 0.7 & & 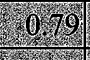 & & & & & & & & & & & \\
\hline & & & & & & & & & & & & & & & & \\
\hline & & & 0.20 & 08 & & 02 & & & & & & & & & & \\
\hline B) 12 & ) & & 08 & & . & 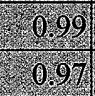 & 9. & & & & & & & & & \\
\hline & & & & & & & & & & & & & & & & \\
\hline & & & 0.92 & & & & & & & & & & & & & \\
\hline & & & & & & & & & & & & & & & & \\
\hline
\end{tabular}


Table 6: Ratios of effective seepage path lengths in " $A$ " series to those in "B" series at $L=\infty$.

\begin{tabular}{|c|c|c|}
\hline \multirow{2}{*}{ Case } & \multicolumn{2}{|c|}{$L=\infty$} \\
\cline { 2 - 3 } & Triangular & Rectangular \\
\hline B1-1/A1-1 & 1.14 & 1.18 \\
\hline B1-2/A1-2 & 1.11 & 1.15 \\
\hline B1-3/A1-3 & 1.10 & 1.14 \\
\hline B2-1/A2-1 & 1.10 & 1.14 \\
\hline B2-2/A2-2 & 1.08 & 1.11 \\
\hline B2-3/A2-3 & 1.07 & 1.10 \\
\hline B3-1/A3-1 & 1.08 & 1.11 \\
\hline B3-2/A3-2 & 1.07 & 1.10 \\
\hline B3-3/A3-3 & 1.06 & 1.08 \\
\hline
\end{tabular}

unity of those ratios is due to the difference of bottom width of impervious zone $B$. When the value of $a^{-1}$ is much larger than the value of $B$, the effective seepage path length becomes independent of the bottom width of impervious zone $B$.

\section{Conclusions}

This paper investigates applicability of the method determining blanket design length based on the analytical solution proposed by Yoshitake et al. (2011) to smaller embankment dams, and demonstrates its validity to the application of half-size of the dams employed in the previous study through the comparison with results computed by BEM. In addition, the reason why the resultant design blanket length of smaller dams is always larger than that of larger ones is shown to be explained by introducing the idea of effective seepage path length. In other words, the effective seepage path lengths of the half-sized dams are found to be almost the same as those of the original dams, keeping the high accuracy of analysis compared to the BEM solution.

\section{References}

[1] Bennett, P.T. (1946): The effect of blankets on seepage through pervious foundations: Trans. ASCE, 111, pp. 215-252.

[2] Fujihara, M., Kobayashi, N., Nishiyama, T., Izumi, T., and Yoshitake Y. (2011): Optimum design of triangular/rectangular soil blanket under given design seepage discharge, IDRE Journal, 276, pp.25-30.

[3] Kobayashi, N., Fujihara, M., Nishiyama, T., Izumi, T., and Yoshitake, Y. (2011): Optimum design of triangular/rectangular soil blanket under given volume of blanket material, IDRE Journal, 276, pp.31-36.

[4] Matsumoto, N. and Yamaguchi, Y. (1989): A study on seepage control for sand and gravel foundation with seepage analysis, Technical Memorandum of PWRI, 2817, pp.1-49 (in Japanese).

[5] Yoshitake, Y., Kobayashi, N., Fujihara, M. and Nishiyama, T. (2011): An analytical solution of the seepage discharge from a reservoir of embankment dam with triangular soil blanket and its applicability, IDRE Journal, 272,pp. 65-71.

Discussion open until June 30, 2013 